\title{
Analysis of the Status Quo of Chinese University Libraries Providing Resource Services to the Public
}

\author{
Yuanfei Gong \\ Zaozhuang University \\ Zaozhuang, China
}

\begin{abstract}
The provision of resources and services by university libraries to the public is an inevitable requirement and the trend of social development. This paper discusses the value and reality of the current Chinese university libraries providing resources and services to the public. The specific problems and contradictions existing in reality are discussed, namely: the contradiction between the priority of the university and the public demand, the contradiction between the priority of resource security and open to the public, and the contradiction between public welfare and compensation. Suggestions based on the actual situation of university libraries are proposed.
\end{abstract}

Keywords—university library; society; resource service

\section{INTRODUCTION}

University libraries are the collection and supply of cultural resources and academic resources, occupying the vast majority of literature resources, especially academic resources. For a long time, service objects of Chinese university libraries are the teachers and students of the school. With the rise and development of the university library alliance in the later period, some university libraries have realized cross-school and inter-regional cooperation and sharing. The scope of service objects expands to the teachers and students of partner institutions. However, Chinese university libraries provide resources and services to the public, which is still in its infancy. At present, institutions that provide book borrowing and resource services to the public are limited to Tsinghua University, Peking University, Wuhan University, and other top-ranking universities in the first- and second-tier cities. Most colleges and universities do not provide resources to the public. For example, in the 2015 survey of the libraries of 45 universities affiliated to Chongqing, there are 15 college libraries open to the public. The open ratio is $33.33 \%$; in 2017 , among the libraries of 83 colleges and universities in Zhejiang Province, there are 40 colleges and universities open to public services, with an open ratio of $48.19 \%$; among the 985 college libraries, there are only 12 colleges [1]. There is information to social users on the Library website. This shows that on a large scale, there is still a gap in the provision of services by university libraries to the public.

\section{ThE NeCESSITY AND VALUE SignifiCANCE OF UNIVERSITY LIBRARY PROVIDING RESOURCES AND SERVICES TO THE PUBLIC}

At present, institutions that undertake the provision of cultural resources to the public are limited to public libraries. Moreover, resource services that public libraries can provide to the public are limited to popular cultural resources and popular science resources and lack academic resources and professional resources. The factors that form the difference between the university library and the public library service object and the different types of resources are: In the early stage, the economic and cultural level of the society is generally low. Moreover, the economic operation mode of the society is dominated by a simple and extensive mode, and the types of work provided by society are mainly laborintensive. Therefore, the public's demand for cultural resources is low, and there is little need for academic resources. However, with the rapid development of social economy and culture in the past 30 years, the proportion of highly educated talents in the total population has increased. At the same time, the rapid development of the economy has made the work type labor-intensive to intellectual-intensive, professional-tech transformation. Moreover, explosive growth and rapid update of knowledge make the resources and services provided by traditional public libraries unable to meet the needs of the public. The public's knowledge resources services provided by the library are transformed from purely popular cultural resources and popular science resources to profound cultural resources and academic resources. This shift makes it difficult for public libraries to effectively meet the needs of the public. Correspondingly, the university library has unique advantages in resources, technology, and professionals.

From the perspective of the value and significance of the university, universities and university libraries should serve the development of society and individuals. The provision of resource services by the university library to the public is not only an inherent requirement of the university as an essential attribute of knowledge production and reproduction, but also an important direction for university libraries in their development. On the one hand, lifelong learning and open universities have increasingly become the mainstream consensus and driving direction of society and government. This makes it necessary for university libraries to provide resource services to more non-school lifelong learners and 
the increasing number of socially available public resources in the society, which are indispensable for professional resources and academic resources, to meet the needs of social development. Service work of university libraries will inevitably be extended by intra-school or inter-school services to public services outside the school. On the other hand, from the international experience, university libraries in Europe and the United States provide resources to the public. In the United States, public universities and private universities that enjoy government financial support are required to open services to the community. The provision of services by the university library to the public has become a common practice. Among them, the community college library mainly provides academic resources for academic training and professional development to the residents in the area. Its comprehensive research university library provides resources for companies, companies or professional institutions, and also provides resource services to the public. From the perspective of Chinese operations, the reason why major universities carry out public services is also an inevitable need for the development of social-economic culture in their regions. It can be seen that providing resources and services to social work is an inevitable direction for the development of university libraries. At the same time, the provision of services by the university libraries to the society has also promoted the public's awareness of colleges and universities and provided good social cognition and support for the development of universities and university libraries.

\section{OBJECTIVE PROBLEMS IN THE PROVISION OF RESOURCE SERVICES BY UNIVERSITY LIBRARIES TO THE PUBLIC}

In recent years, Chinese scholars have made researches on the feasibility and necessity of opening Chinese universities' libraries to the public. This paper discusses the mode of open service of university libraries, the open structure, and many theoretical and practical problems. At present, there are many objective problems in providing Chinese university libraries with resources to the public, which include the regulations and policies and the rules of the university library, the issues of understanding the level of resources and services provided by the universities and libraries to the public, and the specific implementation level.

\section{A. Laws, Policies, and Problems in the Rules and Regulations of University Libraries}

Laws and regulations concerning university libraries include the Higher Education Law of the People's Republic of China and the Regulations of the Library of Ordinary Colleges and Universities issued by the Ministry of Education in 2015. Among them, the Higher Education Law of the People's Republic of China has made macro-level requirements. The Regulations of the Library of Ordinary Colleges and Universities states in Article 3 that libraries should give full play to the role of school personnel training, scientific research, social services, and cultural heritage innovation; in Article 4, paragraph 4, it shall actively participate in the construction and sharing of various resources, give full play to the advantages of information resources and professional services, and serve the society. The behavioral verbs in the two regulations are play, participation, that is, as "permission" rather than "requirement." At the same time, Article 37 states that the library should give full play to the advantages of resources and professions and carry out social-oriented user services on the premise of ensuring the service within the school and the normal working order. According to the requirements of Article 37, some university libraries provide open services to social users, but most of them, especially those in weak areas, avoid providing services to social users with an excuse of ensuring school services and normal work order. At the same time, the second article in the "Public Library Law of the People's Republic of China" states that its subject is a public cultural facility that is freely open to the public and that the university library does not included. Therefore, university libraries are not subject to their jurisdiction. Therefore, at present, there is a gap in the provision of resources and services to the public by university libraries in terms of laws and regulations.

In the university library which has opened its service to the public, the examination of its rules and regulations shows that there are many restrictions and corresponding objective considerations on the public service. For example, in the fifth item of "management measures of Peking University library card and reading card" of Peking University library, the method of receiving off-campus readers of Peking University library is stated in the second item: off-campus readers search books or database in the library. If necessary, the service fee shall be paid according to the standard; Article 3 stipulates that off-campus readers can only read and reproduce prescribed books and periodicals in the library. Article 7 stipulates that visitors to the library must contact the curator's office in advance. With the permission of the curator's office, they can visit the museum within the stipulated time. It can be seen that the library of Peking University is open to the public according to the principle of priority, payment and security.

The Xiamen University Library stated in Article 2 of the first paragraph of the "Administrative Measures for the Study of the Borrowing Certificates of Off-campus Personnel of Xiamen University Library": it must be guaranteed by the faculty and staff members who have officially compiled and held the valid borrowing card of our library; Remarks: The number of people who can guarantee the permit for each faculty and staff is limited to 5 (including 5) [3]. It can be seen that the Xiamen University Library's service to the public is based on the principle of resource security priority. Similar rules and regulations are reflected in other institutions. This can be seen. Three practical problems need to be considered in the provision of services by the university library to the public: the school's priority, paid service, and resource security is preferred. 


\section{B. Problems in the Understanding of Universities and Libraries in Providing Resources and Services to the Public}

At present, both the institutions and the library side have certain deviations from the library's understanding of providing services to the public, especially weak areas and weak institutions. This deviation manifests itself in two forms. First, the work of the library should fully serve the development of the school and the needs of teachers and students. Due to a large number of college teachers and students, and literature resources occupy the main venue resources of the library, the teachers and students of the school already have the objective reality of insufficient venues and insufficient equipment when using the library. Once the public service is opened, the public will inevitably lead to public resources at the venue. The occupation of equipment resources has led to great concerns about the opening of services to society, whether it is college teachers and students or colleges and libraries. The second is that the library's service to the public is based on enterprise users, unit users, and not individual users. Check out the annual reports or work reports of some university libraries. Most annual and work reports do not involve services to the public. Some of the annual and work reports involve the service to the society, but their services are mostly related to the China Higher Education Document Security System (CALIS), college alliances, inter-school or regional cooperation, university library resource sharing, and university library digital resource procurement. Alliance (DRAA) is the mainstay, and there is a lack of services that directly target individual users of the public. It can be seen that there is a discrepancy in the understanding between the institutions and the library.

\section{Specific Implementation Level Issues}

From the examples of the Peking University Library and the Xiamen University Library, it can be found that when the library is open to the public, the primary priority is to give priority to the use of the school and the priority of resource security, followed by the compensation of the service. Compared with the teachers and students on campus, it is difficult to confirm the identity of the public, the identification of work and living places, and the possibility of success. There are many problems at the specific implementation level.

1) It is difficult to identify the public users: There is no mutual connection between university library authentication and the public security system, and between the company and the industrial and commercial system authentication. As a result, the library cannot verify the identity of public users and the places where they work and live, resulting in resource loss. If users are harmed, libraries can hardly be held accountable.

2) Discrimination of paid or unpaid services: There is a difference between the public welfare of university libraries and the public welfare required by the public. The university library is a public institution that is not affiliated with the independent management of the university management system. Its position is the teaching auxiliary unit for the teaching and research service of colleges and universities. Therefore, the readership of the university library is divided into users and social users [4]. The public library is funded by government grants and social contributions from the region, and it only charges a small number of maintenance funds or is completely free when it is open to the public. The funds of the university library are derived from the government's per capita appropriation and office expenses at different levels, the revenue of the school enterprise and the income from various paid services, social investment, and donations. In particular in some universities' financial revenues, and expenditures, the revenues of school-owned enterprises and social investment account for a large proportion. This kind of different funding sources makes the public welfare of the university library's service to the public unable to be consistent with the public library. It should be a service based on public welfare, paid, and reasonable income.

3) The definition of public users: Since the university library should first protect the services of the teachers and students of the school, and the working hours and the effectiveness of the work are objectively constrained, it is impossible to provide services to the entire public. At the same time, the resources of university libraries are academic and professional resources. Therefore, public users served by most university libraries are defined as the public with academic need and professional needs and are mainly enterprise-level and unit-level users. There is neglect of the individual public. At the same time, the provision of resources can also be provided by user type. For example, Zaozhuang College provides some resources and services to its institutions and institutions. Provide online resources and legal books for the courts and procuratorates; provide educational books for the school. Xiamen University provides off-campus resource services and book lending services to its graduates and provides professional resources services to corporate and scientific research institutions. This definition helps the museum to carry out service work, but it is difficult for the general public who has academic resources to meet.

4) Management issues: The institutional setup, staff establishment, work distribution and office fund allocation of university libraries are strictly following the management of public institutions, fixed and fixed posts, and the financial sources come from the unified planning of the institutions. After university libraries open their services to the public, there will inevitably be problems of increased business, increased workload, increased management personnel, clear management institutions, and capital revenue and expenditure. At present, the university library has not yet formed a special management and management organization, and most of the museums will hand over their work to the office of the Library for management affairs, 
and the business librarians will also handle the service affairs.

5) The issue of resource security and resource efficiency protection: The experience of Peking University Library and Xiamen University Library shows that paper resources (books and journals borrowing), online resources (network data query), online reading (using information equipment in the library), and learning venues (use halls) can be provided to public users. Self-study room). However, at the same time, it faces the problem of resource damage, equipment damage, and security in the museum. In terms of resource efficiency, there is a conflict between the use of resources in the school and the use of resources by the public, especially in the use of the equipment and the use of the venue. Therefore, how to ensure the security of resources and the effectiveness of resources is also an objective problem.

\section{THE IDEA OF UNIVERSITY LIBRARY PROVIDING RESOURCES AND SERVICES TO THE PUBLIC}

\section{A. Improving Rules and Regulations and Policies}

Universities and governments are required to have corresponding regulations and policies. Based on the school brand, the concept of serving the society and the perspective of social recognition, the colleges and universities actively carry out corresponding planning for the library to provide resources and services to the public in the work plan and development plan of the institution. At the local government level, universities should be regarded as regional cultural centers and research centers. Recognizing that university libraries provide resources and services to the public, it will effectively promote the development of culture, economy, and science in the region, and is optimized support for local development. The government can introduce policies to promote effective cooperation and integration between university libraries and public libraries, to achieve the interconnection of information and the sharing of resource information. At the same time, the relevant laws and regulations are designed to clarify the standards of the university library under which the public service and the scope of the service, the standard of the service, and the cost of the service must be carried out. Make the public service of university libraries have rules to follow and have laws to follow.

\section{B. Improving Local Government's Financial Support for University Libraries}

The provision of socialized services by university libraries requires the support of funds, social services must be implemented, and the guarantee of funds plays a key role [5]. Local governments have increased financial support for university libraries and promoted the initiative of universities to provide resources and services to the public. Government funding to support university library services is a new concept, a new method, and a new mechanism for the government to provide public cultural services [6].

\section{Improving the Service of University Libraries}

1) To clarify the division of labor between business and management: It is to define the person in charge of business and management department while reasonably allocating workload. The resources security, service form, content, assessment and other aspects involved in the actual service work still need to be further improved [7].

2) To clear fund revenues and expenditures and establish special accounts: Funds from universities or governments, the fee paid by service audiences, and related expenses are collected and disbursed by special accounts.

3) To define service users: University libraries mainly provide academic resources, so the definition of users should be clearly defined as academic and professional users. Users of cultural needs are diverted to public libraries. And realize the information exchange between the university library and the public library, and realize the diversion of the two libraries according to the resource needs of the users.

4) Resource security protection: First, confirm the identity, work location and address of the registered user. It can cooperate with the public security system to verify the authenticity, workplace and household registration information of the identity document. Verify their bank accounts to ensure the true identity of the user. Second, clear security system and the accountability system. The number of security funds should correspond to the value of resources, and the security funds corresponding to resources at different levels should have clear standards. At the same time, punish the damage to the museum resources and violations of rules, until the investigation of legal responsibility. Thirdly, the registered users will be trained and tested before entering the library. Users who have passed the training and testing can enter the library to know the relevant systems.

The guarantee of resource efficiency: First of all, in the service time, the users of the school and public users to provide time-phased services, especially in the use of equipment, the implementation of peak distribution. At the peak of the use of teachers and students in our school, we will serve the school and supplement the service to the public. Especially in the field of stadium resources and equipment resources, the peak hours of school use should be based on the users in the school. Online resources are more widely used because they are online, not in the venue. Secondly, in terms of service fees, deep-level services carry out paid services, and according to the value of resources, a certain amount of service fees are charged to the service objects, to avoid value-free performance consumption. Thirdly, for different professional types of users, different resources are given to serve the resources, thereby reducing the work intensity of the library.

\section{CONCLUSION}

University libraries have rich literature resources and "should" provide services to the public. However, whether 
the university library "can" provide services to the public is subject to objective reality. The difficulty of implementation should not be solved by the library itself, but also requires legal, policy, institutional, financial, and technical support and integration. The provision of public service by university libraries is an inevitable direction, but it cannot be done overnight. It is necessary to explore a path of benign development step by step.

\section{REFERENCES}

[1] Cao Wenzhen, The Predicaments and Countermeasures of the Social Services of Academic Libraries, Library Journal,2018(9), pp. 51-57.

[2] https://www.lib.pku.edu.cn/portal/fw/rgzn/guizhangzhidu/notice2

[3] https://library.xmu.edu.cn/wd/gzzd.htm

[4] Chen Lijuan Lin Yang Liu Haixia, Practice and Thinking of University Libraries Opening to the Public - Taking Xiamen University Library as an Example, 2018(9),pp.101-105.

[5] Tang Yun, Research of Social Servicese of University Library from the Perspective of Public Goods - Taking NUAA library as an example, 2018.04.

[6] Xue Tiao, Reflections on University Library's Participation in Government's Purchase of Public Cultural Servics, Information Research, 2019(5),pp.102-106.

[7] Xu Jian, Research on Social Service of University Libraries in View of Modern Public Culture Service, Lantai World, 2019(2),pp.118-121. 